\title{
Mal-estar na infância: por uma perspectiva da desmedicalização do sofrimento infantil
}

\author{
Disconfort in childhood: for a perspective of demedicalization of \\ child suffering
}

1 Luciana Jaramillo Caruso Azevedo lucianajaramillo@msn.com

1 Especialista em psicoterapia de família e casal; Mestre em psicologia clínica; Doutoranda em psicologia clínica - (PUC-Rio).

\begin{abstract}
Resumo
A progressiva patologização e medicalização dos sofrimentos psíquicos, principalmente aqueles que recaem sobre a infância, tem sido uma tônica contemporânea. Na busca de respostas eficazes para a eliminação radical do mal-estar, dos sofrimentos e dos dissabores da vida, a infância tornou-se alvo de excessivas intervenções medicamentosas profiláticas com vistas a extinguir qualquer vestígio de anormalidade. Entretanto, a excessiva obsessão por detectar indicadores de anomalias, diagnosticar precocemente tudo aquilo que foge ao roteiro da normalidade pode também suprimir as diferenças e capturar as diversas formas de ser criança. Se, por um lado, constatamos a proliferação massiva de critérios diagnósticos, por outro, a partir da clínica, observamos o enclausuramento das crianças nos imperativos contemporâneos de sucesso, saúde perfeita e bem-estar. Nesse sentido, torna-se necessário interrogar qual é o espaço designado ao mal-estar infantil na atualidade. Com vistas a aprofundar essas reflexões teóricas, este estudo visa discutir fatores que estão em jogo na tessitura do mal-estar na infância como as noções de medicalização, os paradigmas contemporâneos e a transformação do sofrimento em adoecimento psíquico.
\end{abstract}

Palavras-chave: Psicanálise. Desmedicalização. Mal-estar. Sofrimento.

\begin{abstract}
The progressive pathologization and medicalization of psychic sufferings, especially those that fall on childhood, has been a contemporary tonic. In the search for effective responses to the radical elimination of life's malaise, suffering and discomfort, childhood has become the target of massive prophylactic drug interventions aimed at eliminating any trace of abnormality. However, too much obsession with detecting indicators of anomalies, early diagnosing anything outside the normal roadmap can also suppress differences and capture the various ways of being a child. If, on the one hand, we find the massive proliferation of diagnostic criteria, on the other, from the clinic, we observe the children's closure on the contemporary imperatives of success, perfect health and well-being. In this sense, it is necessary to question what is the space assigned to child malaise today. In order to deepen these theoretical reflections, this study aims to discuss factors that are at play in the fabric of childhood malaise such as the notions of medicalization, contemporary paradigms and the transformation of suffering into mental illness.
\end{abstract}

Keywords: Psychoanalysis. De-medicalization. Malaise. Suffering.

\section{Como você deve citar?}

AZEVEDO, Luciana Jaramillo Caruso. Mal-estar na infância: por uma perspectiva da desmedicalização do sofrimento infantil. Cadernos UniFOA, Volta Redonda, n. 41, p.85-93, dezembro 2019. 


\section{INTRODUÇÃO}

Partindo da prática clínica, observamos a progressiva patologização dos sofrimentos psíquicos, sobretudo aqueles que recaem sobre a infância. A infância transformou-se em um tempo de vida a ser gerido sob inúmeras expectativas e demandas, produzindo intenso mal-estar tanto para a criança quanto para seus pais e cuidadores. Nesse compasso, a ausência de respostas capazes de eliminar radicalmente o mal-estar psíquico impulsiona a proliferação de um discurso medicalizante dirigido à infância. Em uma de suas principais obras, "Mal-estar na civilização" (1930), Freud é categórico ao considerar que uma das principais fontes de sofrimento humano, talvez a mais dolorosa, tem origem no encontro com o outro. Podemos pensar que essa fonte de sofrimento, oriunda das relações humanas, se impõe na infância e deve ser observada como um elemento crucial nos atendimentos infantis.

O processo de socialização, o estabelecimento das primeiras relações familiares e escolares pode ser fonte precípua de sofrimento para as crianças. Jerusalynsky (2018) afirma existir uma crescente procura de profissionais do campo psi por parte da escola, cujas queixas gravitam em torno da depressão, desmotivação, intolerância e até mesmo linchamentos virtuais. Essas situações denunciam que algo não vai bem. A partir disso, um discurso reducionista se produz e considera tal fenômeno como disfunção, transtorno ou mau funcionamento particular a cada infante, ou seja, de modo isolado.

Embora haja uma preocupação legítima dos profissionais da escola implicados com o sofrimento dos alunos, também se nota uma incessante demanda social que busca a justa palavra para aplacar o mal-estar de forma rápida e eficaz. Há uma tendência de idealizar a infância como um tempo de vida cheio de vivacidade, curiosidade, invenção e brincadeira, cujo estado de permanente criatividade impediria qualquer manifestação de tristeza. No entanto, a pretensão de poupar as crianças de atravessar o mal-estar que se apresenta nos encontros com a alteridade, fundamental para o enfrentamento da castração e da não satisfação plena, acaba por lançá-las a um jogo voraz de performance narcísica, esvaziada da perda necessária que opera na satisfação de cada um (JERUSALINSKY, 2018).

O dispositivo clínico revela aquilo que escapa à tentativa de controle sobre a infância, aquilo que repete e insiste, manifestando-se sob a forma de sintoma e sofrimento psíquico. De modo mais amplo, o sofrimento infantil é crescente a despeito das inúmeras possibilidades de intervenção (WHITAKER, 2017), sendo atualmente nomeado sob insígnias próprias do vocabulário médico, sem levar em conta o lugar que ela ocupa frente às demandas parentais e sociais.

Assim, as crianças vêm sendo convocadas a se enquadrarem em padrões sociais rígidos que demandam o desempenho de múltiplas tarefas em períodos cada vez mais precoces da sua existência. 0 desenvolvimento de habilidades pessoais e sociais, bem como o tempo necessário à constituição psíquica, tem sido solapado pela exigência de aquisição de competências. Em resumo, as crianças são exigidas a se constituírem em meio às exigências contemporâneas de sucesso, saúde e bem-estar (EHRENBERG, 2010).

Nesse ponto, cabe indagar quais são os fatores que têm contribuído para a potencialização do mal-estar na infância. Como conciliar a premência da diferença e da singularidade do sujeito com a demanda contemporânea pela categorização, pelo enquadre nosológico e normalização? Seria o mal-estar na infância uma forma de tentar resistir às intempéries contemporâneas? 


\section{MEDICALIZAÇÃO E SOFRIMENTO PSÍQUICO}

A partir da década de 1950, os psicotrópicos modificaram a concepção de loucura, esvaziaram os manicômios e substituíram a camisa-de-força e os tratamentos de choque por uma redoma medicamentosa. Embora estes não curem as denominadas "doenças mentais", eles revolucionaram as representações do psiquismo e fabricaram um novo homem. Receitado tanto por clínicos gerais quanto por especialistas em psicopatologia, os psicotrópicos têm como efeito normalizar comportamentos e eliminar os sintomas mais dolorosos do sofrimento psíquico sem buscar significação. Dessa maneira, a clínica na atualidade, com os impasses e impossibilidades que se delineiam em seu campo, se impôs como um problema (BIRMAN, 2018).

Na década de 50 também foi formulado o primeiro Manual Diagnóstico e Estatístico de Transtornos Mentais (DSM), da American Psychiatric Association, que consiste em uma classificação de transtornos mentais e critérios associados para facilitar o estabelecimento de diagnósticos mais confiáveis desses transtornos. Com sucessivas edições ao longo dos últimos 60 anos, tornou-se uma referência para a prática clínica na área da saúde mental.

Porém, a abordagem descritiva adotada desde o DSM - III se orienta a partir de definições dos distúrbios geralmente limitadas às descrições de suas características clínicas, entendendo-se por características clínicas apenas os sinais e sintomas comportamentais facilmente identificáveis que requeiram uma quantidade mínima de interferência da parte do observador. Os diagnósticos passaram a ser "sindrômicos", no sentido fraco do termo, e não "nosológicos", ou seja, pretendem ser a mera descrição objetiva da ocorrência de um determinado grupo de sinais e sintomas. Com efeito, o termo "transtorno" responde a essa nova apreensão, apesar ou justamente por sua imprecisão. (TENÓRIO, 2016). De fato, torna-se premente o questionamento acerca da dimensão ético-política do diagnóstico psiquiátrico e da contínua expansão de ferramentas diagnósticas.

Segundo Birman (2018), a reformatação nosográfica do DSM, desde os anos 1980, foi crucial, posto que evidencia uma aliança teórica estabelecida entre os discursos da psiquiatria biológica, do cognitivismo e da terapia comportamental. Todos esses discursos encontram-se inscritos no paradigma naturalista de cientificidade. Apesar dos seus idealizadores proclamarem essa descrição como sendo ateórica, a descrição baseada em síndromes/transtornos/disfunções (no lugar da categoria de enfermidade) evidencia de forma eloquente as linhas de força e as coordenadas teóricas dos campos discursivos que foram enfatizados.

Assim, a série de DSM, após os anos 1980, foi caracterizada pela suspensão da leitura histórica da enfermidade. Em seu lugar, se enunciou a categoria de síndrome. A resultante teórica dessa articulação passou a descrever transtornos e não mais enfermidades. Com isso, diferentemente da leitura da enfermidade, na qual se articulavam intimamente as categorias de espaço e do tempo, com a regulação deste sobre aquele, na leitura da síndrome, o que se impõe como contrapartida é a descrição dos transtornos e das disfunções centradas na categoria do espaço. Portanto, nas novas versões do DSM o que se descreve são transtornos, síndromes e disfunções, em que a dimensão histórica e temporal da enfermidade foi suspensa e silenciada (BIRMAN, 2018).

Tenório (2016) ressalta que, desde a terceira revisão do Manual Diagnóstico e Estatístico de Transtornos Mentais da Associação Psiquiátrica Americana (DSM - III), houve um abandono da noção de "psicose" enquanto categoria de fundo, que designava uma classe de patologias diferente da "neurose". Essa nova inflexão representou também uma mudança de paradigma, cujo efeito foi o enfraquecimento da descrição das doenças mentais apoiada nos pressupostos psicodinâmicos, em favor de uma abordagem fisicalista da patologia mental. Uma das consequências dessa mudança, em termos de nosografia e da clínica, foi a medicalização das condições antes associadas à subjetividade, tais como ansiedade, tristeza, ideias obsessivas, fobias, comportamentos sexuais, entre outros. 
Os estudos da medicalização se direcionam para a análise da intervenção política da medicina no corpo social, por meio do estabelecimento de normas morais de conduta, prescrição e proscrição de comportamentos, o que tornaria os indivíduos dependentes dos saberes produzidos pelos agentes educativo-terapêuticos. Data do século XVIII, com o nascimento da medicina moderna e da Higiene, 0 início da intervenção médica na intimidade das pessoas, fazendo com que os profissionais da saúde e, sobretudo educadores se tornassem especialistas a quem todos deveriam recorrer em busca de soluções para seus males domésticos (GAUDENZI \& ORTEGA, 2012).

O discurso médico difundido na mídia naturaliza o sofrimento infantil e se apresenta na escola de forma marcante. A psicologização parece ceder lugar, hoje, à psiquiatrização da escola e dos respectivos discursos familiar e escolar. É relativamente comum que educadores utilizem diagnósticos diante da observação de certos "problemas de aprendizagem" e encaminhem os alunos para avaliação psiquiátrica, neurológica ou psicológica (GUARIDO, 2007). Essas questões complexas estão longe de ter respostas simples, uma vez que a trama dorsal dessa discussão encontra-se primordialmente assentada sobre os cuidados dispensados às crianças.

Brant e Minayo-Gomes (2004) destacam que, na atualidade, parece existir uma tendência a banir o sofrimento e a transformar o sofrimento em adoecimento. Para Freud (1920), o sofrimento é o estado de expectativa diante do perigo e da preparação para ele, ainda que seja um perigo desconhecido (angústia); ou medo, quando ele é conhecido; ou susto, quando o sujeito topa com um perigo sem estar preparado para enfrentá-lo. Portanto, o sofrimento se configura como uma reação, uma manifestação da insistência em viver em um ambiente que, na maioria das vezes, não lhe é favorável.

Conceitualmente, sofrimento e dor não se confundem, contudo não se distinguem com facilidade. A palavra sofrimento tem sido associada ao psíquico, ao mental, enquanto a palavra dor é geralmente remetida a algo localizado no corpo (BRANT \& MINAYO-GOMES, 2004).

No que se refere ao sofrimento, Roudinesco (2000) acredita que o sofrimento psíquico tem se manifestado constantemente sob a forma de depressão, cuja presença se transformou em uma epidemia das sociedades democráticas atuais. A autora aponta para uma mudança paradigmática ou a substituição de um paradigma por outro. Essa mudança é acompanhada pela substituição e valorização dos processos psicológicos de normalização em detrimento das diferentes formas de exploração do inconsciente. Tratado como depressão, o conflito neurótico contemporâneo parece não decorrer de nenhuma causalidade psíquica oriunda do inconsciente. No entanto, o inconsciente ressurge através do corpo, opondo uma forte resistência às disciplinas e práticas que visam repeli-lo. Pode-se dizer que esse novo campo terapêutico promoveria a normalização das individualidades e dos laços sociais pelo silêncio dos registros do sujeito e da singularidade.

No fluxo paradigmático contemporâneo que compreende a performance, o silenciamento da subjetividade e a medicalização como pilares constitutivos, Lipovetsky (1989) propõe que o universo do espetáculo e das idealizações que não cessam de ir ao encontro da vida. Lipovetsky (1989) entende que existe uma cultura de massa amplamente difundida e destinada a satisfazer a necessidade de evasão dos indivíduos, cujos efeitos de longo prazo são diversos e atingem todas as camadas sociais. Essa cultura de massa teve como função histórica determinante a reorientação das atitudes individuais e coletivas, bem como a difusão de novos padrões de vida, seguindo novos referentes ideológicos e modelos existenciais. A cultura de massa foi um vetor essencial do individualismo contemporâneo, sua obra hipnótica apenas sacraliza o indivíduo em ficção, engrandece a felicidade, tornando irreais as existências concretas. Para o autor, esse tipo de cultura faz viver por procuração imaginária um indivíduo sonambúlico, despossuído de si mesmo pelas figuras encantadas no imaginário. 
Birman (2010) aponta para uma transformação fundamental que ocorreu na economia simbólica da lei moral, que passou a ser regulada pelo imperativo do sujeito de atingir a condição de felicidade. No entanto, se a felicidade se transformou em um imperativo irrepreensível, isso se deve à democratização do espaço social, que concedeu a todos a pretensão de igualdade. Em uma sociedade supostamente democrática, que transformou a igualdade em um dos seus ideais primordiais e em um dos alicerces da cidadania, a aspiração à felicidade passou a ser pleiteada como algo da ordem do direito. 0 mandato de ser feliz, "custe o que custar", se coloca hoje efetivamente como uma demanda inequívoca. Em decorrência disso, a depressão passou a se impor como uma das modalidades maiores de sofrimento, posto que evidencia o fracasso performático do sujeito. É nesse contexto imperativo de felicidade e bem-estar que constatamos o aumento progressivo dos sintomas nas crianças.

No entanto, não se pode perder de vista que o diagnóstico também expressa um código cultural que engloba determinantes sociais, econômicos, desequilíbrios de poder, e não apenas disfunções bioquímicas. Cabe questionar até que ponto esse mal-estar vivido pelas crianças não seria uma forma de resistência aos excessivos mandatos culturais que se apresentam de forma marcante na escola e na família.

No que tange especificamente ao sofrimento psíquico infantil, pensamos ser imprescindível a utilização da teoria psicanalítica para pensarmos esse campo do saber além dos dispositivos normativos medicalizantes.

\section{SINTOMAS INFANTIS E DESDOBRAMENTOS DO MAL-ESTAR: POR UMA PERSPECTIVA DESMEDICALIZANTE}

De acordo com Lima (2005), uma série de mal-estares humanos vem sofrendo um deslocamento progressivo de sentido. A pluralidade de abordagens contempladas, quando se tratava de explicar as vicissitudes individuais, tem sido solapada por concepções fisicalistas que tendem a reduzi-la a sua dimensão biológica. Os comportamentos que traziam desconforto podiam ser considerados como tendo causas médicas, mas também eram tomados como efeito de ações de instâncias, como a família, a escola, conflitos relacionais, entre outros fatores. Hoje, essas perspectivas são rechaçadas e tidas como equivocadas ou depreciadas como "anticientíficas". Isso acontece em benefício de abordagens que localizam no corpo as razões dos dissabores experimentados na vida.

Por outro lado, a teoria psicanalítica enfatiza a relevância primordial da incidência do desejo parental na constituição da subjetividade infantil. Uma criança condensa, para aquele (s) a deseja (m), uma expectativa que exige satisfação e convida o sujeito a ocupar o lugar do objeto preenchedor (FLESLER, 2012). Freud (1914) não apenas equiparou simbolicamente a criança ao majestoso Narciso e ao objeto que falta a um adulto, como também expressou que ela é capaz de realizar a presença desse objeto na fantasia do adulto. A mãe antecipa a existência do sujeito, quando ele não é sequer vivente. Flesler (2012) esclarece que, em função dessa antecipação materna, uma representação do bebê é forjada antes mesmo que ele esteja formado. Assim, na imaginação, a mãe poderá lhe dar um corpo separado do seu. Antecipando para o bebê o seu lugar enlaçado, preexistente e necessário para o seu engendramento, a função da antecipação materna se desdobra em uma bivalência: ser ou não ser o falo.

Segundo a leitura de Tenório (2016), ao retomar os textos de Freud e Lacan, o sujeito humano se constitui como sujeito em resposta às injunções que giram em torno da herança simbólica paterna e do chamado do sexual (chamado que é tanto da ordem da satisfação corporal quanto de uma tomada de posição, da assunção de responsabilidades, de aceder aos encargos inerentes ao seu sexo). Conforme as formulações de Freud (1914), a constituição do sujeito corresponde à introdução no psiquismo desses elementos subjetivos, no entanto alojados no inconsciente, como um saber inconsciente (recalcados). 
Esse saber opera no sujeito à revelia, tanto impulsionando, enquanto desejo, a responder às exigências da vida e do desejo, quanto produzindo (como sintoma) os pontos de impasse, de impossibilidade de franquear uma determinada dimensão, de dificuldade de fazer alguma coisa, ou mesmo na forma dos sintomas repertoriados pela tradição clínica (ansiosos, depressivos, dissociativos, obsessivos etc.).

A forma particular de articulação do sintoma da criança apontada por Lacan no texto "Notas sobre a criança" (1969) é profundamente trabalhada no âmbito da clínica infantil. Nesse caso, há uma articulação significante que se sobrepõe ao sintoma e se mostra aberta às intervenções do analista. Para Lacan (1969), o sintoma da criança é capaz de responder pelo que há de sintomático na estrutura familiar, representando a verdade do par familiar. Essa primeira definição do sintoma tem a lei do interdito do incesto como uma de suas variantes, na qual se inscreve o significante paterno como aquele que conjuga a lei com o desejo. Em outras palavras, existe uma articulação significante que sobredetermina o sintoma infantil e que, por se referir à verdade do casal parental, está ligado à metáfora paterna, dando acesso à significação fálica. Nesse contexto, a criança responde com o sintoma para fazer face ao desejo materno que, desde a sua origem, está articulado à metáfora paterna.

Cada ser humano é marcado pela relação real que tem com o pai e a mãe, do a priori simbólico que herda antes mesmo do seu nascimento. Em suma, cada criança está marcada por essa situação real. 0 sintoma de impotência que uma criança manifesta é uma ressonância às angústias ou aos processos reativos às angústias dos pais. Essa impotência é, muitas vezes, a ilustração em escala reduzida da impotência de um dos pais, deslocada do nível em que ela se manifesta no adulto para o nível de organização libidinal precoce da criança. Naquele ponto em que a linguagem termina, o comportamento continua a falar (DOLTO, 2004).

Dolto (2004) esclarece que cada caso patológico é a pantomima de um discurso não verbalizado que significa a afirmação ou a anulação da dinâmica do sujeito. A família, outrora sustentáculo e refúgio, nada mais é agora do que um lugar transitório de crescimento, no qual penetram pelos olhos e ouvidos os ecos do mundo. Mais do que nunca, cada ser humano, cujo corpo está protegido contra os acompanhamentos e resultados de todos os incidentes de saúde, apercebe-se de que suas impotências afetivas e psíquicas o colocam em perigo de perder seu equilíbrio mental.

Na análise do caso do pequeno Hans, Freud (1909) constata o aparecimento de sintomas transitórios em quase toda criança em determinada fase, sugerindo que, ao invés de constituírem uma patologia, eles podem apontar para um momento de organização psíquica. Desse modo, a apresentação do caso Hans é um exemplo da constituição da neurose infantil, que seria o resultado da constituição do aparelho psíquico ou da instauração do recalcamento originário. Nesse sentido, a propósito do caso Hans e, partindo da premissa de que no princípio da fobia está a angústia, Flesler (2012) argumenta que as várias expressões da angústia foram rebatizadas nos últimos tempos, de modo precipitado, como "transtorno de ansiedade".

Deparamo-nos na clínica com crianças que não encontram graça no viver, sem curiosidade, apáticas ou excessivamente ansiosas. Crianças sem tempo ou lugar para criar, inventar, brincar, fantasiar, posto que estão imersas em um mundo com agendas cheias e imaginando o futuro não como fonte de possíveis realizações, mas de sucessivos compromissos. Não se pode perder de vista que, ao educar as crianças, desde o pragmático princípio de super equipá-las para o futuro, submetendo-as a um excesso de ofertas de informação e de consumo, pode-se estar privando delas algo fundamental: o encontro com um certo vazio fundamental que é central para desejar e poder inventar. Elas se encontram duplamente assoladas pela sombra do objeto enquanto consumidoras consumidas: por um lado, abarrotadas de objetos-fetiche com os quais não brincam e as deixam como espectadoras em lugar de servirem de apoio para um fantasiar. Por outro lado, as crianças são elas mesmas consumidas por estarem submetidas à condição de realizarem a demanda de um bom produto do investimento narcísico dos pais. (JERUSALYSKY, 2018). Por essas razões, enclausurar o mal-estar infantil e seu respectivo 
sintoma em um discurso proveniente da psiquiatria biológica torna-se por demais simplista e danoso, no que se refere à construção da subjetividade infantil.

Tenório (2000) compreende por "desmedicalizar" o ato de romper com o circuito segundo o qual a um problema trazido pelo paciente, o profissional responde com uma "resposta-remédio". Essa resposta pode se apresentar como efetivamente um medicamento, um diagnóstico, um encaminhamento ou até mesmo uma interpretação precipitada. Assim, torna-se possível desmedicalizar para subjetivar. Desmedicalizar a queixa para subjetivar a demanda.

O tempo necessário à constituição psíquica não coincide com o tempo articulado conforme o discurso capitalista. No entanto, enquanto clínicos, cabe a tentativa de fazer operar em certa medida uma lógica que permita ao sujeito-criança o desenvolvimento de recursos psíquicos para se haver com o mal-estar que atravessa todo sujeito.

\section{CONSIDERAÇÕES FINAIS}

A psicanálise com crianças demanda permanente aprofundamento em função das suas especificidades. Entre elas encontra-se a articulação estrutural entre o sintoma infantil e a fantasia, o discurso e o desejo parentais. A teoria psicanalítica compreende um arsenal teórico-prático consistente que possui potencial para fazer frente à perspectiva medicalizante, em especial, na abordagem sobre o sintoma. Se, por um lado, o discurso médico atribui uma materialidade biológica na origem do sintoma, sobre o qual incidem suas intervenções, por outro lado, a psicanálise atribui um sentido a ele, intimamente articulado à existência particular da qual o sujeito é portador.

Na neurose infantil, que pode ser entendida como o ponto culminante do processo de construção da realidade psíquica do sujeito, os sintomas constituem uma tentativa da criança de interpretar os significantes enigmáticos propostos pelo adulto e que Ihe propiciam atravessar o Édipo, separando-se da lógica binária em que se encontra com a mãe.

O mal-estar observado na clínica infantil nos faz ratificar que o sujeito do desejo também é um sujeito histórico, ético e político que traz a marca da cultura na qual está imerso. Por isso, é imperativo compreender a medicalização como um aspecto paradigmático contemporâneo que incide sobre $a$ infância, captura a diversidade, silencia o sujeito e se relaciona diretamente com a cultura do espetáculo e da performance.

O mal-estar pode insurgir como resistência, sob a forma de depressão, ansiedade, agressividade, dificuldade de aprendizagem ou outras "categorias" medicalizáveis. Por isso, faz-se necessário estabelecer a distinção entre a medicalização da angústia infantil, o tratamento efetivo de uma patologia e a otimização de habilidades hipervalorizadas pela cultura. Estes três elementos parecem estar embrincados na contemporaneidade.

Diante da complexidade do tema, não se pode ratificar um modelo baseado estritamente em evidências que busca a relação simplista entre uma causa única e sua respectiva resposta padrão. $\mathrm{Na}$ contramão do que vem ocorrendo, é preciso considerar dispositivos que contribuam com formulações de respostas diversas e potentes para problemas complexos.

Com efeito, a proposta de uma concepção "desmedicalizante" visa a aposta em uma clínica que opere no sentido de implicar o sujeito no sintoma do qual se queixa. Para tanto, é importante instituir uma escuta para além da avaliação diagnóstica apressada e de uma indicação apriorística de conduta. 


\section{REFERÊNCIAS}

AGUIAR, Adriano. A psiquiatria no divã: entre as ciências da vida e a medicalização da existência. Rio de Janeiro, RJ: Relume Dumará, 2004.

BIRMAN, Joel. Muitas felicidades?! 0 imperativo de ser feliz na contemporaneidade. Ser feliz hoje: reflexões sobre o imperativo da felicidade. Rio de Janeiro: Editora FGV, p. 27-47, 2010.

BIRMAN, Joel. Genealogia da clínica. Revista Latinoamericana de Psicopatologia Fundamental, v. 21, n. 3, p. 442-464, 2018.

BRANT, L. C., \& MINAYO-GOMES, C. A transformação do sofrimento em adoecimento: do nascimento da clínica a psicodinâmica do trabalho. Ciência e Saúde Coletiva, v. 9, p. 213-223, 2004.

DOLTO, Françoise. Prefácio. In: A primeira entrevista em psicanálise. 6. ed. Rio de Janeiro: Campus, 2004.

EHRENBERG, Alain. 0 culto da performance: da aventura empreendedora à depressão nervosa. Aparecida: Ideias e Letras, 2010.

FLESLER, Alba. A psicanálise de crianças e o lugar dos pais. Rio de Janeiro: Zahar, 2012.

FREUD, Sigmund. (1909). Análise de uma fobia em um menino de cinco anos: o pequeno Hans. Rio de Janeiro, RJ: Imago, 1976.

FREUD, Sigmund. (1914). Sobre o narcisismo: uma introdução. Edição Standard brasileira das obras completas de Freud, v. XIV. Rio de Janeiro: Imago, 1976.

FREUD, Sigmund (1920). Além do princípio do prazer. Edição Standard brasileira das obras completas de Freud, v. XIV. Rio de Janeiro: Imago, 1976.

GAUDENZI, Paula.; ORTEGA, Francisco. O estatuto da medicalização e as interpretações de Ivan Illich e Michel Foucault como ferramentas conceituais para o estudo da desmedicalização. Interface Comunicação, Saúde, Educação, v. 16, n.40, p. 21-34, 2012.

GUARIDO, Renata. A medicalização do sofrimento psíquico: considerações sobre o discurso psiquiátrico e seus efeitos na educação. Educação e Pesquisa, v. 33, n.1, p.151-161, 2007.

GUARIDO, Renata. A biologização da vida e algumas implicações do discurso médico sobre a educação. In: Conselho Regional de Psicologia de São Paulo \& Grupo Interinstitucional Queixa Escolar (Orgs.), Medicalização de crianças e adolescentes: conflitos silenciados pela redução de questões sociais a doenças de indivíduos (pp. 27-39). São Paulo, SP. Casa do Psicólogo, 2010.

JERUSALINSKY, Julieta. A melancolização na infância contemporânea: entre o linchamento virtual e a política do "no touch". Cadernos de Psicanálise - SPCRJ, v. 34, n. 1, p. 26-33, 2018.

LACAN, Jacques. Outros escritos. Rio de Janeiro: Jorge Zahar, 1969.

LIMA, Rossano Cabral. Somos todos desatentos?: o TDA/H e a construção das bioidentidades. Rio de Janeiro: Relumé Dumará, 2005. 
LIPOVETSKY, Gilles. O império do efêmero. São Paulo: Companhia das Letras, 1989.

ROUDINESCO, Elisabeth. A família em desordem. Rio de Janeiro: Zahar, 2000.

TENÓRIO, Fernando. Desmedicalizar e subjetivar: A especificidade da clínica da recepção. Cadernos IPUB, v.6, n.17, p. 79-91, 2000.

TENÓRIO, Fernando. Psicose e esquizofrenia: efeitos das mudanças nas classificações psiquiátricas sobre a abordagem clínica e teórica das doenças mentais. História, Ciências, Saúde-Manguinhos, v. 23, n. 4, p. 941-963, 2016.

WHITAKER, R. A anatomia de uma epidemia. Rio de Janeiro: Editora Fiocruz, 2017. 